\title{
Evaluation of the probability of miners' protection while using filtering respirators
}

\author{
Serhii Cheberiachko ${ }^{1 *}$, Olena Yavorska $^{1}$, Oleh Deriuhin ${ }^{2}$, and Andrii Yavorskyi $^{3}$ \\ ${ }^{1}$ Dnipro University of Technology, Department of Labour Protection and Civil Safety, \\ 19 Yavornytskoho Ave., 49005 Dnipro, Ukraine \\ ${ }^{2}$ Dnipro University of Technology, Department of Transportation Management, 19 Yavornytskoho \\ Ave., 49005 Dnipro, Ukraine \\ ${ }^{3}$ Dnipro University of Technology, Department of Mining Engineering and Education, \\ 19 Yavornytskoho Ave., 49005 Dnipro, Ukraine
}

\begin{abstract}
Objective of the research is to evaluate the probability of deterioration of the protection of miners' respiratory organs while using filtering respirators in terms of coal mines under the coal mine conditions and to elaborate recommendations for the reduction of possible occupational disease risks. A Markovian process theory has been applied to solve the formulated problem. It has been determined that the probability of deterioration of the protection of a worker wearing a filtering respirator is up to $50 \%$, which is stipulated by the lack of corresponding training as for the correct filtering respirator use, negligence of the physical load and its duration during the respirator selection, and possible mistakes during its operation. Reduction of the occupational disease risks is possible only in terms of the use of high-quality filtering respirator under conditions of its correct selection, maintenance and use by the trained miners with the preliminary checking of its relevance to the coal mine conditions. It has been shown that the development of a respiratory protection programme at an enterprise is the efficient tool to provide a miner with high-quality and appropriate filtering devices for the respiratory protection.
\end{abstract}

\section{Introduction}

Irrespective of the requirements of legislation [1,2], which regulate the use of filtering respiratory protective equipment (RPE) only in the extreme cases, when it is impossible to reduce the concentration of harmful substances in the air of the mine working zones down to the safe indices with the help of engineering and technical measures, they are widely used at coal-mining enterprises. In the USA, production enterprises spend about USD 5 bln per year to provide their workers with filtering RPE. In particular, about 40000 of filtering $\mathrm{RPE}$ are required for coal companies a year [3]. The indicated sum of money increases considerably, taking into consideration the processes of maintaining, testing the compliance with the operating modes, and training the workers to use the equipment efficiently. One should be very careful with the organization of the protective process with the use of

\footnotetext{
*Corresponding author: sicheb@ukr.net
} 
filtering RPE. That process consists of several successive actions: determination of the concentration of harmful substances in the air of a mine working zone, climatic conditions, work mode; evaluation of the occupational risks related to the use of filtering RPE; substantiation of the RPE use in terms of its functional purpose and operating conditions; training to master the skills of RPE efficient use; organization of RPE storage and maintenance according to the requirements.

Organization of such a costly approach is the necessary condition to reduce cases of pneumoconiosis of the respiratory organs. If the requirements are not met, then the insurance costs increase to cover treatment and rehabilitation of the workers. For instance, in 2017, China registered 21719 occupational diseases of miners; among them, lungs diseases accounted for $44.83 \%$ [4]. In the USA, after considerable reduction in the disease incidences down to $10 \%$ in the late 1990 s, some states have demonstrated its growth up to $20.6 \%$ over the recent years being a significant problem highlighted by the Healthcare Department [5]. In Ukraine, according to the analysis of the published open sources of information, there are socalled residual dustiness levels in the mine workings; those levels are by dozen times more than the boundary admissible ones being, according to the official data, the cause of the pneumoconiosis incidences in more than 2000 people per year [6].

Insufficient attention is paid to a problem of the evaluation of the professional risks while using filtering RPE in terms of a coal mine; according to the opinion of different experts, that evaluation will favour the reduction of the development of occupational diseases [7, 8]. It should be mentioned that several international standards consider the procedure to be obligatory $[2,9,10]$. Note that the mentioned normative documents have no explanations concerning the origin, weighted evaluation, and recommendations how to eliminate or reduce the risks of occupational diseases in the workers wearing filtering RPE. However, to evaluate any occupational risks, it is also required to identify the hazardous factors which, under certain conditions, will lead to an undesirable event. According to [9], the hazardous factors related to the use of filtering RPE under the coal mine conditions, may be divided into two main groups: group 1 - certain mistakes during the RPE selection; group 2 - inefficiency of its operation. It is clear that in each of the mentioned case a miner will not be protected completely; thus, the issues require further studying.

Analysis of the papers published over the last year [7 - 16] makes it possible to draw a conclusion on the fact that great attention is paid to the problems of the evaluation of the development of occupational disease risks. In particular, the emphasis is placed on the development of innovative research methods, templates, and report forms with the prediction of risks. Those methods involve computing devices, which increase the productivity, help process and complement the defects of the collected statistic data, provide better control of the level of exposition doses, and specify the stage-to-stage development of the diseases related to the occupational activities [11-13].

However, there are quite a few scientific studies dealing with the evaluation of the probability of the miners' respiratory organs disease taking into account the use of filtering RPE under the coal mine conditions. First of all, that is connected with the complexity of determining a coefficient of protection under production conditions; moreover, that coefficient is rather a variable value [17]. That value depends on many components: miners' training level, preliminary checking of the compliance of filtering RPDs with the anthropomorphic characteristics of the users' faces, consideration of the working conditions, periods of RPE operations, and other factors for the conditions of a coal-mining enterprise. Monitoring of the protective efficiency of filtering RPE is rather a complex task [18]. Nevertheless, calculation of the value of exponential dust zone entering the miner's lungs through filters leaves the researchers asking numerous questions. The problem is intensified by the fact that nowadays there is no unified approach to the determination of the probability of dust sediment distribution within the human respiratory tract $[19,20]$. 
Thus, there arises the necessity to search for new ways, which would allow evaluating possible risks while using filtering RPE, which would be also rather simple and clear for workers. For instance, that can be the analysis of the efficiency of a "man-filtering RPE" system, which will help specify the risks related to the inefficient or unskilled use of filtering respirators.

Objective of the research is to evaluate the probability of deterioration of the miners' respiratory organs protection while using filtering respirators under the coal mine conditions.

\section{Methodology}

To solve the formulated problem, use a Markovian process theory. Assume that a "man filtering RPD" system may be in the operating condition when adequate protection of the respiratory organs is provided by correct RPE selection based on the following: conditions of a coal-mining enterprises, physical abilities of the miners, their training, and compulsory checking of the protective properties at the specific workplace. The system may be in the deteriorated conditions - when certain inconsistencies arise due to the unaccounted climatic conditions, physical load while performing the production operations, working schedule, necessity in communication, duration of wearing, use of other individual protective equipment (IPE), slipping of a half-mask/mask due to head movements. The system may be in the emergency conditions - when filtering RPE does not provide the required protection due to some critical mistakes (unaccounted level of the contamination of the working zone air, anthropomorphic characteristics of a user, protective period of filters etc.). In this context, intensity of the transitions $\lambda$ between the described states is characterized by certain density of the event probability. Represent the described process in the form of a corresponding graph (Fig. 1).

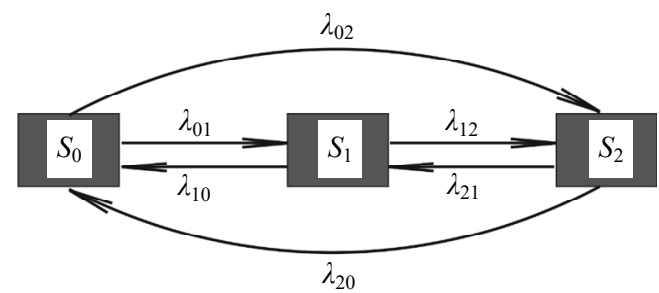

Fig. 1. Graph of the state of changes in the protective degree of a "man - protecting RPE" system.

\section{Statement of the problem}

When workers perform their duties under harmful conditions, they are required to use several individual protection devices simultaneously. That results in certain inconveniences related to combination of protective devices, their proper selection, and unhandiness. In particular, helmet liner made in the form of balaclava, is practically incompatible with RPD. When earpieces are used, it is required to put the liner on and off because if earpieces are placed upon the balaclava, then protective parameters of HPD worsen. Moreover, topical problem is to provide the communication without putting the HPD off and to make it possible to hear warning signals. Thus, there is the necessity in reliable fixation on a face (so that the mask does not slip and form additional gaps along the obturation line resulting in considerable deterioration of insulating properties) [7].

For the first time, specialists of Physical and Chemical Institute of Environmental Protection and Human of the Ministry of Education and Sciences of Ukraine and NAS of 
Ukraine have developed a complex individual protection device of fast adjustment (CIPD); the device has combined balaclava 1 equipped with the corresponding filtering half-masks 4, noise-attenuating elements 2 and thermal accumulating elements 3 (Fig. 1). All the components are connected with the help of the shank end of a valve unit which is built into the related mounting openings of the balaclava and half-mask and fixed with the help of a nut.

Fig. 1 shows that the adequate miners' protection is at the state $S_{0}$. However, under the effect of certain circumstances (necessity in communication, fatigue due to the working period, improper organization of the working and resting time, effect of the increased temperature or air moisture within the working zone etc.), arising with certain intensity $\lambda_{01}$, a worker can make a noncritical mistake. That mistake will result in the deterioration of the respiratory organs protection (e.g. due to the formed suctions of the unfiltered air between a face and a mask along the obturation line). Consequently, a "man - filtering RPE" system will transfer in some intermediate state $S_{1}$, in terms of which certain protective level is provided but some amount of hazardous admixtures enters the under-mask space due to the specified reason. A worker may operate further being in that state or, under the effect of other factors (value of the air dustiness, complicated breathing due to the considerable physical load, defects in the fixation system, sudden accidents), the emergency state $S_{2}$ will begin. If the mistake or incompliance is detected, then there will be return to the initial state $S_{0}$. At the same time, serious violations during the selection or operation (no requirements stipulated by the instruction, training, control of the proper operation) will result immediately in the emergency state $S_{2}$ with the intensity $\lambda_{02}$ leaving out the intermediate state. There are several variants of the development of further events. A critical mistake was detected and the system with the immediate corrections and with the intensity $\lambda_{20}$ would return to the operating condition $S_{0}$; or the defect could not be eliminated completely, and the system with the intensity $\lambda_{21}$ would return to the deteriorated state $S_{1}$. Having identified the flow of events with the help of the constructed graph of probable states, it is possible to simulate probabilities of changes in the protection level of a "man filtering RPE" system $P_{0}(t), P_{1}(t) P_{2}(t)$ as the time functions in terms of the KolmogorovChapman differential equations:

$$
\left\{\begin{array}{l}
\frac{d}{d t} P_{0}(t)=-\left(\lambda_{01}+\lambda_{02}\right) \cdot P_{0}(t)+\lambda_{01} \cdot P_{1}(t)+\lambda_{20} \cdot P_{2}(t) \\
\frac{d}{d t} P_{1}(t)=\lambda_{01} \cdot P_{0}(t)-\left(\lambda_{10}+\lambda_{12}\right) \cdot P_{1}(t)+\lambda_{21} \cdot P_{2}(t) \\
\frac{d}{d t} P_{2}(t)=\lambda_{02} \cdot P_{0}(t)+\lambda_{12} \cdot P_{1}(t)-\left(\lambda_{21}+\lambda_{20}\right) \cdot P_{2}(t)
\end{array}\right.
$$

with the given condition that:

$$
P_{0}(t)+P_{1}(t)+P_{2}(t)=1
$$

The equation may be represented in the linear matrix system introducing for the consideration the vector-function $\vec{P}_{0}(t)=\left[P_{0}(t), P_{1}(t), P_{2}(t)\right]$ and the matrix of intensities:

$$
N=\left(\begin{array}{ccc}
-\left(\lambda_{01}+\lambda_{02}\right) & \lambda_{10} & \lambda_{20} \\
\lambda_{10} & -\left(\lambda_{01}+\lambda_{02}\right) & \lambda_{21} \\
\lambda_{20} & \lambda_{12} & -\left(\lambda_{21}+\lambda_{20}\right)
\end{array}\right),
$$

then: 


$$
\left\{\begin{array}{l}
\frac{d}{d t} \vec{P}(t)=N \vec{P}(t) \\
l \vec{P}(t)=\sum_{i=0}^{3} P_{i}(0)=1, P_{i}(0) \geq 0 .
\end{array}\right.
$$

The initial data to calculate probabilities of a "man - filtering RPE" system being in the corresponding state were taken from the analysis of the studies, dealing with the consideration of the RPE protection efficiency under the production conditions and published in several papers [20 - 27]. Their analysis is represented in Table 1.

Table 1. Analysis of the scientific research results.

\begin{tabular}{|l|c|c|c|c|c|}
\hline $\begin{array}{c}\text { Author of the } \\
\text { research }\end{array}$ & $\begin{array}{c}\text { Area of the } \\
\text { research }\end{array}$ & $\begin{array}{c}\text { Total } \\
\text { number of } \\
\text { the } \\
\text { participants }\end{array}$ & $\begin{array}{c}\text { Number of } \\
\text { the } \\
\text { participants } \\
\text { with the } \\
\text { recorded } \\
\text { mistakes }\end{array}$ & $\begin{array}{c}\text { Number of the } \\
\text { participants } \\
\text { which results } \\
\text { were not taken } \\
\text { into account }\end{array}$ & $\begin{array}{c}\text { Average } \\
\text { coefficient } \\
\text { of } \\
\text { protection } \\
\text { of filtering } \\
\text { RPE }\end{array}$ \\
\hline Nelson, T.J. [27] & $\begin{array}{c}\text { Operations } \\
\text { with } \\
\text { asbestos }\end{array}$ & 26 & 18 & 3 & $168 \pm 5.8$ \\
\hline Colton, C.E. [28] & $\begin{array}{c}\text { Ship } \\
\text { repairing }\end{array}$ & 47 & 24 & 5 & $205 \pm 3.5$ \\
\hline Tannahill, S.N. [29] & $\begin{array}{c}\text { Asbestos } \\
\text { removal }\end{array}$ & 30 & 19 & 2 & $120 \pm 4.7$ \\
\hline Johnston, A.R. [30] & Grinding & 25 & 16 & 2 & $1100 \pm 5.3$ \\
\hline Holinko, V.I. [31] & Coal mine & 30 & 14 & 4 & $16 \pm 2.7$ \\
\hline
\end{tabular}

Basing on the analysis of the represented data - total number of workers, their number with the adequate protection while using filtering RPE, number of the recorded cases of inadequate protection, number of mistakes made while studying - intensities of transitions between the states of a "man - filtering RPE" system have been calculated for a group of 10 people (the number was selected to simplify the calculations) (Table 2).

Table 2. Initial data to calculate changes in the state of a "man - filtering RPE"system.

\begin{tabular}{|l|c|c|}
\hline \multicolumn{1}{|c|}{ Parameters } & $\begin{array}{c}\text { Number of } \\
\text { units/situations }\end{array}$ & $\begin{array}{c}\text { Intensity of } \\
\text { occurring, } \lambda\end{array}$ \\
\hline Number of miners at a site, people & 10 & $\lambda_{01}=0.6$ \\
\hline $\begin{array}{l}\text { Number of miners, in terms of which certain mistakes } \\
\text { during the filtering RPE operation were recorded, people }\end{array}$ & 6 & $\lambda_{10}=0.2$ \\
\hline $\begin{array}{l}\text { Number of miners, who corrected their mistakes during } \\
\text { the operations, people }\end{array}$ & 2 & $\lambda_{02}=0.4$ \\
\hline $\begin{array}{l}\text { Number of miners with the detected critical mistakes } \\
\text { during selection and operation of filtering RPE, which } \\
\text { resulted in the emergency state, people }\end{array}$ & 4 & $\lambda_{20}=0.1$ \\
\hline $\begin{array}{l}\text { Number of miners, who managed to correct completely } \\
\text { their critical mistakes during their operation, people }\end{array}$ & 3 & $\lambda_{21}=0.3$ \\
\hline $\begin{array}{l}\text { Number of miners, who managed to correct partially } \\
\text { their critical mistakes during their operation with } \\
\text { filtering RPE, people }\end{array}$ & 4 & $\lambda_{12}=0.4$ \\
\hline $\begin{array}{l}\text { Number of miners, whose incorrect operation of filtering } \\
\text { RPE resulted in the emergency state, people }\end{array}$ & 1 & \\
\hline
\end{tabular}




\section{Results and their discussion}

A matrix of transitions was developed on the basis of the specified indices (Table 2). The matrix is as follows

$$
N=\left(\begin{array}{ccc}
-1 & 0.2 & 0.1 \\
0.6 & -0.6 & 0.3 \\
0.4 & 0.4 & -0.4
\end{array}\right),
$$

Then, a system of Kolmogorov-Chapman equations (1) taking into consideration the intensity matrix (5) will be represented in the following form:

$$
\left\{\begin{array}{l}
\frac{d}{d t} P_{0}(t)=-P_{0}(t)+0.2 \cdot P_{1}(t)+0.1 \cdot P_{2}(t) \\
\frac{d}{d t} P_{1}(t)=0.6 \cdot P_{0}(t)-0.6 \cdot P_{1}(t)+0.3 \cdot P_{2}(t) \\
\frac{d}{d t} P_{2}(t)=0.4 \cdot P_{0}(t)+0.4 \cdot P_{1}(t)-0.4 \cdot P_{2}(t)
\end{array}\right.
$$

To solve the equation system (6), it is possible to use the Gaussian method; then, $P_{0}=0.1 ; P_{1}=0.4 ; P_{2}=0.5$. The obtained indices show that in terms of the described example, when there is no corresponding preparation and checking, the development of probable emergency in a "man-filtering RPE" system is 50\%. That is rather an unfavourable result, which requires certain managerial and organizational actions to reduce the effect of the unfavourable factors resulting in the mistakes during the RPE selection and operation under the conditions of a coal-mining enterprise.

Solve a system of differential equation s with the help of Mathcad 14 software to identify a boundary level of the probability distribution within certain period of time (sixhour working shift). Fig. 2 shows the calculation results.

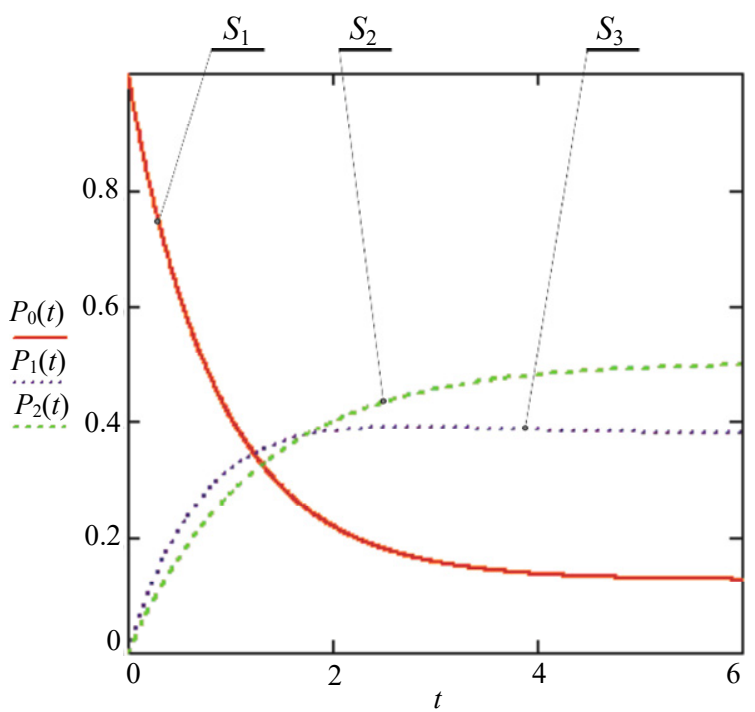

Fig. 2. Curves of the dependences of probabilities $P_{0}, P_{1}, P_{2}$ of the states of a "man - filtering RPE" system $\left(S_{0}, S_{1}, S_{2}\right)$ on time $t$ (hours). 
Analysis of the curves of the dependences of probabilities $P_{0}, P_{1}, P_{2}$ of the states of a "man - filtering RPE" system $\left(S_{0}, S_{1}, S_{2}\right)$ on time $t$ (hours) makes it possible to draw the following conclusion: probability of the adequate miner's protection in terms of the RPE use (state $S_{0}$ ), i.e. capable to work, will be about $20 \%$ at the end of the working shift. First of all, that state is stipulated by the incorrect or unskilled use of filtering RPE under complicated and nonuniform working conditions even in terms of one and the same workplace. The experts have emphasized that fact many times during their analysis of the factors deteriorating the RPE protective properties [19-21, 24]. Analyze those factors and give recommendations as for the reduction of their effect on the development of emergency states in a "man - filtering RPE" system.

Basing on the collected information on the conditions of RPE use and preservation of RPE efficiency during its operation, one can say that the most important mistake, resulting even in the fatality, is the inconsistency of the RPE functional purpose. That is the situation when the selected RPE does not correspond either to the toxicant type or to the protection class (especially, when the oxygen concentration is lower than 18\%). In this case, the workers are unprotected due to the crude violations of the corresponding instructions or negligence of those administrators of a coal-mining enterprise who are responsible for the RPE selection. Next mistake, which will also result in the deterioration of the protective properties and will favour the increasing occupational risks, is the incompliance of a mask with the anthropomorphic parameters of the miner's face; it is defined by the insulating properties of half-masks. That is the reason why it is required to provide checking of the mask-face contact density for a user at the stage of the filtering RPE selection, which follows the specification of the required protection class and decision-making as for its type. Table 3 contains the recommendations as for reduction of the effect of the represented causes of deterioration of the protective properties of filtering respirators during their selection.

Table 3. Recommendations to reduce the occupational disease risks due to the mistakes during the RPE selection.

\begin{tabular}{|c|c|c|}
\hline \multicolumn{2}{|c|}{ Mistakes } & \multirow{2}{*}{$\begin{array}{l}\text { Recommendations to reduce } \\
\text { occupational disease risks }\end{array}$} \\
\hline Case & Consequences & \\
\hline $\begin{array}{l}1 \text { The selected respirator does } \\
\text { not correspond to its functional } \\
\text { purpose }\end{array}$ & $\begin{array}{l}\text { Adequate protection of the } \\
\text { respiratory organs is not } \\
\text { provided }\end{array}$ & $\begin{array}{l}\text { It is required to replace the } \\
\text { respirator: to select a } \\
\text { respirator of } \\
\text { corresponding type and } \\
\text { protection class }\end{array}$ \\
\hline $\begin{array}{l}2 \text { A respirator is selected } \\
\text { without considering the } \\
\text { conditions for its use } \\
2.1 \text { oxygen concentration in the } \\
\text { air of a working zone is }<18 \%\end{array}$ & $\begin{array}{l}\text { First, there is dizziness, } \\
\text { weakness, increased } \\
\text { heartbeating; in terms of critical } \\
\text { oxygen content }<<18 \% \text {, there } \\
\text { are convulsions and death }\end{array}$ & $\begin{array}{l}1 \text { Ventilate a working zone } \\
2 \text { Use insulating RPE instead } \\
\text { of the filtering ones }\end{array}$ \\
\hline $\begin{array}{l}2.2 \text { level of the air } \\
\text { contamination of a working } \\
\text { zone exceeds the limits of the } \\
\text { safe respirator use }\end{array}$ & $\begin{array}{l}\text { Toxicants (aerodisperse } \\
\text { particles), gases, or vapours } \\
\text { enter the under-mask space of } \\
\text { the respirator }\end{array}$ & $\begin{array}{l}\text { Select a respirator of the } \\
\text { corresponding protection } \\
\text { class }\end{array}$ \\
\hline $\begin{array}{l}2.3 \text { climatic conditions } \\
\text { (temperature and air moisture) }\end{array}$ & $\begin{array}{l}\text { Deterioration of the ergonomic } \\
\text { indices of respirators due to the } \\
\text { growing breathing resistance, } \\
\text { violation of the heat balance, } \\
\text { moisture accumulation on a face } \\
\text { and within the under-mask } \\
\text { space }\end{array}$ & $\begin{array}{l}\text { Use a respirator equipped } \\
\text { with the valve system }\end{array}$ \\
\hline
\end{tabular}


Continuation of the Table 3

\begin{tabular}{|l|l|l|}
\hline \multicolumn{1}{|c|}{ Mistakes } & \multicolumn{1}{|c|}{$\begin{array}{l}\text { Recommendations to reduce } \\
\text { occupational disease risks }\end{array}$} \\
\hline $\begin{array}{l}\text { 3 Undefined compatibility of a } \\
\text { mask with the } \\
\text { anthropomorphic size of the } \\
\text { user's face }\end{array}$ & $\begin{array}{l}\text { Insufficient protection level due } \\
\text { to the lack of hermiticity of the } \\
\text { undermask space, which will } \\
\text { factor into the increased } \\
\text { entering of the harmful } \\
\text { substances in the lungs }\end{array}$ & $\begin{array}{l}\text { Provide checking of the RPE } \\
\text { compatibility to the user's } \\
\text { parameters applying one of } \\
\text { the available methods }\end{array}$ \\
\hline $\begin{array}{l}\text { 4 Possibility of mechanical } \\
\text { damages and water-falling on } \\
\text { a filtering mask }\end{array}$ & $\begin{array}{l}\text { Insufficient protection level due } \\
\text { to the formation of additional } \\
\text { suction channels as a result of } \\
\text { the filter damage }\end{array}$ & $\begin{array}{l}\text { Use respirators with the } \\
\text { elastomeric masks }\end{array}$ \\
\hline
\end{tabular}

The most widespread mistakes while RPE using in terms of coal-mining enterprises are as follows: miners lack training to know how to use RPE properly; they are not aware of the RPD functioning principles, its structure, and limitations of its use (due to the work speed, necessity in communication, and use of other RPE). In addition, miners do not know the principles of proper RPE putting on/off, recognition of possible damages, and performing the required checking before its use. Besides, it is important to provide the required maintenance for the filtering RPE after their use, their cleaning and disinfection. If the workers lack that knowledge and skills, probability of the development of occupational disease risks increases due to the deterioration of the protection and ergonomic indices of a protective device. That makes the employers organize corresponding procedures for workers' training, checking the operating propertied of filtering RPE at a workplace, identifying and replacing the damaged units, and proper storage. Table 4 gives recommendations as for the reduction of the development of occupational diseases risks due to the mistakes while operating filtering RPE.

Table 4. Recommendations to reduce the occupational disease risks due to the mistakes while operating filtering RPE.

\begin{tabular}{|c|c|c|}
\hline \multicolumn{2}{|r|}{ Mistakes } & \multirow{2}{*}{$\begin{array}{l}\text { Recommendations to reduce the } \\
\text { occupational disease risks }\end{array}$} \\
\hline Case & Consequences & \\
\hline $\begin{array}{l}\text { Users are not trained } \\
\text { to apply RPE }\end{array}$ & $\begin{array}{l}\text { Lack of adequate protection due to } \\
\text { the inability to use RPE }\end{array}$ & $\begin{array}{l}\text { Organization of the compulsory } \\
\text { workers' training as for the proper } \\
\text { RPE use }\end{array}$ \\
\hline $\begin{array}{l}\text { Operating conditions } \\
\text { are not taken into } \\
\text { consideration }\end{array}$ & $\begin{array}{l}\text { Deterioration of the protective and } \\
\text { ergonomic RPE properties due to } \\
\text { the additional load, frequent filter } \\
\text { replacement, improper maintenance, } \\
\text { and the vision area restriction }\end{array}$ & $\begin{array}{l}\text { Organization of measures to } \\
\text { check the adequacy of RPE } \\
\text { selection at a workplace }\end{array}$ \\
\hline $\begin{array}{lr}\text { Necessity } & \text { in } \\
\text { communication while } \\
\text { performing } \\
\text { operations is not } \\
\text { taken } \\
\text { consideration }\end{array}$ & $\begin{array}{l}\text { Insufficient protection level due to } \\
\text { the need of taking the mask off; } \\
\text { entering of harmful aerosols in the } \\
\text { lungs during that period }\end{array}$ & $\begin{array}{l}\text { Use of respirators with the } \\
\text { intercommunication systems }\end{array}$ \\
\hline $\begin{array}{lr}\begin{array}{l}\text { Use of } \\
\text { or/and } \\
\text { masks }\end{array} & \text { damaged } \\
\text { worn-out }\end{array}$ & $\begin{array}{l}\text { Insufficient protection level due to } \\
\text { the deterioration of operational } \\
\text { characteristics of respirators }\end{array}$ & $\begin{array}{l}\text { Organization of the corresponding } \\
\text { maintenance, checking, and } \\
\text { replacement of the damaged RPE } \\
\text { components }\end{array}$ \\
\hline
\end{tabular}


Analysis of the information given in Tables 3 and 4 demonstrates that some of the indicated risks may be reduced only by using high-quality filtering RPE with the appropriately represented information as for marking, maintenance, periods of protective action, periods of replacement, and performance of the corresponding training for the workers. The training should also include the emergency drill, e.g. possible decrease in the oxygen concentration; cases of instantly occurred dangerous methane concentration, exceeding RPE protective properties; methane explosions etc. That requires the development of the corresponding programme of respiratory protection at a coal mine and cooperation only with the responsible manufacturers of filtering RPE, which are monitoring constantly their production processes from the raw material purchase up to the manufacturing of high-quality end products. Note that according to p. 8.1.4.2 [2], a manufacturer or a supplier of filtering RPE should provide the information on the proper risks to have coordination with a consumer. The indicated requirement stipulates the necessity in better integration of companies-manufacturers and companies-consumers of those products, which will make it possible to ensure mutual control of the technological processes of the efficient filtering RPE operation. Consequently, the product quality and safety of the workers, using those products, will be improved as well.

It is clear that despite the correct filtering RPE selection, which may involve experienced professionals (e.g. from the institutions of industrial labour hygiene who are experts in the technical characteristics of filtering RPE and a procedure of specifying the values of the occupation risks related to their use), it is important to ensure solution of the organizational problems. The main problem is to encourage miners to use RPE properly that results in the successful implementation of the respiratory protection programme [25, 26]. Any filtering RPE is the additional load on a worker during his/her work. Its size depends considerably on the hazardous factors and other implemented general-purpose IPE $[27-30]$. If there is the need in using filtering RPE, the workers should understand all the responsibility in case of their refusal to use them; the workers should be aware of the development of occupational diseases and deterioration of their life quality as well as economic losses due to the treatment of the occupational diseases. It is essential that the workers understand the danger and admit it realizing that all the inconveniences cannot be compared with the possible diseases. That will stipulate responsible attitude to both the selection and use of filtering RPE.

It should be stressed that leading experts from the research institutions as well as manufacturers of filtering RPE, who are able to explain in detail any features of the operation of their products, are to be involved to provide the efficient programme of respiratory protection, to formulate its main statements and educational programmes, and to implement the monitoring systems.

\section{Conclusions}

In terms of the represented initial conditions and according to the results of the evaluated probability of the state of a "man - filtering RPE" system, it has been defined that miners' wearing the properly functioning filtering RPE up to the end of their work shift is $20 \%$, while probability of the emergency state is $50 \%$. First of all, that is stipulated by the lack of corresponding training on the proper operation of filtering RPE, by the necessity of communication and use of other incompatible IPE, by neglecting the work pace and duration, and by the possible mistakes during the RPE selection.

Corresponding recommendations, which will help reduce the risks of the development of the emergency state of a "man-filtering RPE", have been elaborated. The recommendations mean the appropriate overall monitoring of the process of RPE use, timely identification of failures in its operation, and correcting the mistakes made by a 
worker during his/her work under conditions of mine workings.

Occupational risks may be reduces only in terms of the use of high-quality filtering RPE including its correct selection, maintenance and appropriate application by the trained miners; moreover, the miners should have preliminary tests as for their correspondence to the facial anthropomorphic parameters and the performed operations. It has been shown that the development of a programme for the efficient respiratory protection is the important tool to provide the reliable protection of the miners' respiratory organs.

This work was conducted within the project "Geotechnological bases of power and chemical complexes formation in the coal mining region" (State registration No. 0120U102084).

\section{References}

1. ISO/IEC 31010:2009. (2009). Risk management - Risk assessment techniques. Geneva: International Organization for Standardization.

2. ISO 45001:2018. (2018). Occupational health and safety management systems - Requirements with guidance for use. Geneva: International Organization for Standardization.

3. Respiratory Protection Equipment Market worth 7.28 Billion USD by 2022 Markets and Markets. Respiratory Protection Equipment Market by Product Type (Air-purifying Respirators, Supplied Air Respirators), End-use Industry (Healthcare \& pharmaceuticals, Defense \& Public Safety Services, Oil \& Gas, Manufacturing, Mining) - Global Forecast to 2022 (2017).

4. Han, S., Chen, H., Harvey, M-A., Stemp, E., \& Cliff, D. (2018). Focusing on Coal Workers' Lung Diseases: A Comparative Analysis of China, Australia, and the United States. International Journal of Environmental Research and Public Health, 15(11), 2565. https://doi.org/10.3390/ijerph15112565

5. Blackley Blackley, D. J., Halldin, C. N., \& Laney, A. S. (2018). Continued Increase in Prevalence of Coal Workers' Pneumoconiosis in the United States, 1970 - 2017. American Journal of Public Health, 108(9), 1220-1222. https://doi.org/10.2105/ajph.2018.304517

6. Occupational safety and health in the mining industry in Ukraine. (2018). International Labour Organization. DWT and Country Office for Central and Eastern Europe. Kyiv, Ukraine.

7. Aneziris, O.N., Papazoglou, I.A., Konstantinidou, M., \& Nivolianitou, Z. (2014). Integrated risk assessment for LNG terminals. Journal of Loss Prevention in the Process Industries, (28), 23-35. https://doi.org/10.1016/j.jlp.2013.07.014

8. Ramesh, R., Prabu, M., Magibalan, S., \& Senthilkumar, P. (2017). Hazard Identification and Risk Assessment in Automotive Industry. International Journal of ChemTech Research, 10(4), 352-358.

9. Directive 89/391/EEC - OSH "Framework Directive". (2018). On the introduction of measures to encourage improvements in the safety and health of workers at work - "Framework Directive". Brussels: European Agency for Safety and Health at Work.

10. Lachapelle, E., \& Voca, N. (2014). OHSAS 18001. Occupational health and safety management systems - Requirements. Canada: PECB Headquarters.

11. Di Noia, A., Martino, A., Montanari, P., \& Rizzi, A. (2019). Supervised machine learning techniques and genetic optimization for occupational diseases risk prediction. Soft Computing, 24(6), 4393-4406. https://doi.org/10.1007/s00500-019-04200-2

12. Benavides, F., Ramada, J., Ubalde-Lopez, M., Delclos, G., \& Serra, C. (2019). A Hospital Occupational Diseases Unit: An Experience to Increase the Recognition of Occupational Disease. La Medicina del Lavoro, 110(4), 278-284. https://doi.org/10.23749/mdl.v110i4.8138

13. Van der Molen, \& Frings-Dresen. (2019). Occupational Diseases: From Cure to Prevention. Journal of Clinical Medicine, 8(10), 1681. https://doi.org/10.3390/jcm8101681

14. Shafiei, M., Ghasemian, A., Eslami, M., Nojoomi, F., \& Rajabi-Vardanjani, H. (2019). Risk factors and control strategies for silicotuberculosis as an occupational disease. New Microbes and New Infections, (27), 75-77. https://doi.org/10.1016/j.nmni.2018.11.002 
15. Rezapour, M., Khorrami, Z., Tabe, R., \& Khanjani, N. (2019). The Prevalence of Occupational Risk Factors and Occupational Diseases in Kerman, Iran. International Journal of Epidemiologic Research, 6(2), 65-69. https://doi.org/10.15171/ijer.2019.12

16. Di Piazza, A., Argo, A., Scalici, E., Guajana, A., Picone, D., \& Lo Re, G. (2019). Occupational Diseases: Asbestosis and Mesothelioma in Forensic Practice. Radiology in Forensic Medicine, 189-195. https://doi.org/10.1007/978-3-319-96737-0 17

17. Carrico, R.M., Coty, M.B., Goss, L.K., \& LaJoie, A.S. (2007). Changing health care worker behavior in relation to respiratory disease transmission with a novel training approach that uses biosimulation. American Journal of Infection Control, 35(1), 14-19. https://doi.org/10.1016/j.ajic.2005.12.013

18. Bergman, M.S., Zhuang, Z., Hanson, D., Heimbuch, B.K., McDonald, M.J., Palmiero, A.J., ... Wander, J.D. (2013). Development of an Advanced Respirator Fit-Test Headform. Journal of

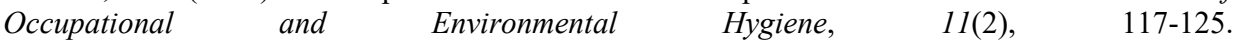
https://doi.org/10.1080/15459624.2013.816434

19. Nicas, M. (2001). Modeling Turbulent Diffusion and Advection of Indoor Air Contaminants by Markov Chains. American Industrial Hygiene Association Journal, 62(2), 149-158. https://doi.org/10.1080/15298660108984617

20. Nelson, T.J. (1995). The Assigned Protection Factor of 10 for Half-mask Respirators. American Industrial Hygiene Association 5ournal, 717-724. https://doi.org/10.1080/15428119591016755

21. Colton, C.E., \& Bidwell, J.O. (1995). A Comparison of the Workplace Performance of Two Different Types of High-Efficiency CE Filters on Half-Facepiece Respirators. In American Industrial Hygiene Conference and Exposition (pp. 34-45). Kansas City, Missouri, USA.

22. Tannahill, S.N., Willey, R.J., \& Jackson, M.H. (1990). Workplace protection factors of hse approved negative pressure full-facepiece dust respirators during asbestos stripping: preliminary findings. The Annals of Occupational Hygiene, 34(6), 547-552. https://doi.org/10.1093/annhyg/34.6.547

23. Johnston, A.R., \& Mullins, H.E. (1987). Workplace Protection Factor Study for Airborne Meal Dusts. In American Industrial Hygiene Conference and Exposition (pp. 64-75). Kansas City, Missouri, USA.

24. Golinko, V. I., Yavorskaya, E. A., Cheberyachko, Y. I., Cheberyachko, S. I. (2015). Analysis of protective value of dust-fighting respirators and its effect on dust burden of miners. Gornyi Zhurnal, 76-80. https://doi.org/10.17580/gzh.2016.03.16

25. Franna, R., \& Gaspar, R.M. (2011). Expectation Hypothesis Bias: Risk Aversion versus Stochastic Adjustments.. SSRN Electronic Journal. ADVANCE working paper Series, n. 1/2011. https://doi.org/10.2139/ssrn.2417268

26. Bansal, R., \& Yaron, A. (2004). Risks for the Long Run: A Potential Resolution of Asset Pricing Puzzles. The Journal of Finance, 59(4), 1481-1509. https://doi.org/10.1111/j.15406261.2004.00670.x

27. Golinko, V.I., Cheberyachko, S.I., Yavorskaya, E.A., \& Cheberyachko, Y.I. (2016). Analysis of protective value of dust-fighting respirators and its effect on dust burden of miners. Gornyi Zhurnal, (3), 76-80.

28. Cheberyachko, S., Yavors'ka, O., \& Morozova, T. (2013). Study of mechanical half-mask pressure along obturation bar. Annual Scientific-Technical Colletion - Mining of Mineral Deposits 2013, 317-322. https://doi.org/10.1201/b16354-58

29. Cheberiachko, S., Yavors'ka, O., Radchuk, D., \& Yavorskyi, A. (2018). Respiratory Protection Provided by Negative Pressure Half Mask Filtering Respirators in Coal Mines. Solid State Phenomena, (277), 232-240. https://doi.org/10.4028/www.scientific.net/ssp.277.232

30. Graveling, R., Sanchez-Jimenez, A., Lewis, C., \& Groat, S. (2011). Protecting Respiratory Health: What Should be the Constituents of an Effective RPE programme? The Annals of Occupational Hygiene, 55(3), 230-238. https://doi.org/10.1093/annhyg/meq098 